change and ultimately generation of theory (Greenwood, 1994). Six focus groups $(n=43)$ and a survey were conducted to formally evaluate the implementation of the dedicated support within a specialist hospice in the UK.

Results The PAR approach was a useful framework to promote ongoing change within a dynamic hospice environment. Interim results found that the Admiral Nurses project provides a useful template to inform change within a hospice environment; demonstrate the breadth of impact of the service from a patient, family and professional perspective; and highlight how such an initiative can be the catalyst for effective strategic and operational change.

Conclusion The numbers of people with dementia is increasing world-wide, and issues around effective and specialist support are challenging. Expanding the hospice role to include patients with dementia requires investment in dementia specialist nurses to complement existing hospice expertise.

\section{P-87 HOSPICE-ENABLED DEMENTIA CARE: JOINT WORKING BETWEEN A HOSPICE AND AN ACUTE DEMENTIA CARE UNIT}

${ }^{1}$ Anna Wolkowski, ${ }^{2}$ Emma Wolverson. ${ }^{1}$ Dove House Hospice, Hull, UK; ${ }^{2}$ Humber Teaching NHS Foundation Trust, Hull, UK

\subsection{6/bmjspcare-2018-hospiceabs.112}

Introduction Dementia is a life-limiting illness that is currently our biggest public health challenge. Despite being the leading cause of death in 2016 (Office for National Statistics, 2017), people living with dementia remain disadvantaged in terms of access to palliative and end of life care (Care Quality Commission, 2016). Hospices have the expertise to play a crucial role in driving improvements, but this challenge cannot be faced alone; what has been called for is 'hospice enabled dementia care' (Hospice UK, 2015) based on strong partnership working.

Background In 2017, a 14 bedded acute NHS mental health inpatient unit for people with dementia needed a temporary home while its own accommodation was being refurbished. It was agreed that this would be provided in an unoccupied wing of the local independent hospice. Our presentation is the story of this project and how the two services seized the chance to make the most of this unique opportunity of mental health and specialist palliative care services to share skills and expertise and work towards developing sustainable collaborative relationships.

Project description The presentation will take the audience on a journey beginning by introducing both services and the challenges that they each faced alone in providing end of life care for people with dementia. Then we will share reflections on the steps we undertook to develop relationships and share skills such as our programme of joint lunch and learn events and a buddy system. We talk about how strong relationships were formed based on shared values and passion for high quality person-centred care. We reflect on our experience of providing hospice-enabled dementia care by working creatively together, illustrated through case vignettes. Finally, we will share our evaluations and recommendations for others looking to improve end of life care for people with dementia.

\section{P-88 DEMENTIA PATHWAY - FROM DIAGNOSIS TO END OF LIFE}

Erika Lipscombe, Emma Hanson. Rowans Hospice, Hampshire, UK

10.1136/bmjspcare-2018-hospiceabs. 113

The City Council invited local charities to tender to provide services that would contribute to sustaining and improving dementia diagnosis rates and enable the city to become a dementia friendly city.

Three charities came together and were successful in demonstrating how they would work in partnership to support a person with dementia from diagnosis to end of life working alongside statutory provision. The key objective for the new service was to support the person diagnosed with dementia and their carers through the allocation of a named 'contact' facilitating people and their carers to access and use services. The hospice in partnership with the service employs two Clinical Nurse Specialists (CNSs) who lead the complex dementia and end of life care support pathway aspect. Referrals are via a single point of access, including self-referrals and are prioritised according to a 'RAG' system leading to either 'social' support or the support of a CNS.

Support for patients with dementia and their carer is through a 'drop in' service where they can meet a member of the team, also through carer support groups, activity groups and training for carers. A Saturday morning coffee group has been set up to support those carers who work in the week and cannot attend week-day events; the service is now working later in the evenings. Clients are supported to remain in their preferred place for care and following death bereavement support is provided.

The service reports through KPIs to the Council; the two CNSs have seen 180 patients with complex dementia, and have supported 40 people with dementia to die within their 'preferred' place of care, working alongside the carers preand post- bereavement. An interesting observation is that the numbers of those people with dementia needing in-patient care through the hospice has not increased.

\section{P-89 DELIVERING TRAINING TO IMPLEMENT AND EMBED THE NAMASTE CARE PROGRAMME IN CARE HOMES}

Sara Paterson, Jacqueline Bennett, Sally Barber. Countess Mountbatten Hospice, Southampton, UK

10.1136/bmjspcare-2018-hospiceabs.114

Aim Dementia is a growing issue and increasingly part of national and international policy. At Countess Mountbatten Hospice we have secured funding for an 18 month pilot of the Namaste Care Programme, which will look at engaging care homes in providing a daily programme that aims to enhance and maintain quality of life for individuals with advanced dementia, at end of life.

Methods To develop robust training that will lead to the successful implementation of the programme, and through supportive working via visits and close correspondence, embed the programme into their daily care delivery for those individuals. This training is done by an initial full day 